\title{
Consumer Adoption of Digital Technologies for Lifestyle Monitoring
}

\author{
Luca Gastaldi \\ Department of Management, \\ Economics and Industrial Engineering, \\ Politecnico di Milano \\ Milano, Italy \\ luca.gastaldi@polimi.it
}

\author{
Emanuele Lettieri \\ Department of Management, \\ Economics and Industrial Engineering, \\ Politecnico di Milano \\ Milano, Italy \\ emanuele.lettieri@polimi.it
}

\author{
Marco Mandolfo \\ Department of Management, \\ Economics and Industrial Engineering, \\ Politecnico di Milano \\ Milano, Italy \\ marco.mandolfo@polimi.it
}

\begin{abstract}
Despite their potential, the adoption of wearable devices has been relatively slow when compared to other digital technologies. This paper investigates, grounding on the Theory of Planned Behavior, the adoption by end users of digital technologies for lifestyle monitoring. Data on consumers' perception and usage of wearable devices have been collected through a survey administered to 1,000 Italian citizens and further analyzed through a Structural Equation Model approach. Results show that, above the functional value of the device, external influence, particularly doctor opinion, exerts an essential role in adoption. Online health literacy proves to be a relevant factor as well, showing the importance of cultural patterns in wearables diffusion. Implications for academicians, practitioners and policy-makers are provided.
\end{abstract}

Keywords-wearable devices; technologies for lifestyle monitoring; theory of planned behavior; online health literacy; perceived doctor opinion;

\section{INTRODUCTION}

Wearables devices have emerged as rapidly developing technologies with the potential to change people's lifestyles and improve their wellbeing, decisions, and behaviors [1]. Wearable systems are portable and can enable individuals to benefit from analyses that have previously been confined to research laboratories [2]. Compared to smart phones and laptop computers, wearable devices offer consumers more flexibility, accessibility, possibility to use while the user is in motion, and possibility to use non-keyboard commands such as voice and hand gestures. Despite all these benefits, the adoption of wearable devices has been relatively slow when compared to mainstream technologies [3]. Hence, both practitioners and academics show a growing interest in understanding the influential factors that explain a continued adoption of wearable devices [4]. Technology adoption processes, indeed, represent a fundamental piece of knowledge to favor the diffusion of innovation [5] especially where such a diffusion may support the adoption of virtuous practices by users [6], as in the case of wearables. In contexts in which public healthcare systems are exposed to budgetary constraints, disease prevention, also through the support to functional, healthy conducts and lifestyles becomes of the essence to ensure welfare sustainability [7]. In this study, following a rich stream of literature on technology adoption (e.g. [8]-[10]), we analyze the adoption by end users of digital technologies for lifestyle monitoring, in order to understand possible drivers of their adoption and to draw implications for academicians, practitioners and policy makers.

\section{THEORY AND HYPOTHESES}

Studies that have investigated the influential factors in adopting wearable technologies have applied different approaches, and most of them have based their study designs on the well-known technology acceptance model and related consumer psychology theories [11]-[13]. Grounding on such studies, we advance that the Theory of Planned Behavior (TPB)[14] may be used to model the adoption of digital technologies in lifestyle monitoring. TPB was firstly proposed as an extension of the Theory of Reasoned Action, which was developed to predict voluntary behaviours and to understand their determinants [15]. The TPB postulates that behavioural Intention is the first predictor of behaviour since it captures people's motivations to perform it, showing how hard they are willing to try to perform it and how much effort they are planning to exercise. Intention is determined by three conceptually independents constructs: Attitude toward the behaviour (A), Subjective Norms (SN) and Perceived Behavioural Control (PBC). Attitude refers to the overall evaluation of the behaviour (positive or negative), and the more positive is the Attitude toward a behaviour, the higher will be the intention to perform it. Subjective Norms reflect the perceived social pressure by important others to perform the behaviour and they positively affect behavioural intention. Perceived Behavioural Control refers to the perceived ease or difficulty of engaging in the behaviour: the more people feel to have control over the behaviour, the more likely they will try to engage in it [14]. TPB is a widely applied theory to understand and predict human behaviors [16]-[18] and has been proved particularly effective in predicting health behaviors [19]-[21], thus representing a valid conceptual and theoretical background for this study. In particular, given the specificities of the behavior investigated, related to healthcare, we propose to focus our attention on a specific subjective norm, i.e. the doctor opinion. Adoption of technology for preventive healthcare, indeed, is not only pushed by individual beliefs, but is motivated by social pressure as well [6], [22]. This focus could also improve our 
understanding of the healthcare systems in the adoption processes of these technologies. For this reason, in this study we will test the following hypotheses:

Hla. The perceived utility of using digital technologies to monitor lifestyle has a positive influence on the development of a positive attitude toward this behavior.

H1b. The attitude of using digital technologies to monitor lifestyle has a positive influence over the intention to do it.

H1c. The perceived control over the use of digital technologies to monitor lifestyle has a positive influence over the intention of doing it.

Hld. The perceived control over the use of digital technologies to monitor lifestyle has a positive influence over the implementation of this behavior.

Hle. The intention to use digital technologies to monitor lifestyle has a positive influence over the implementation of this behavior.

H2. The perceived doctor opinion on the monitoring of daily activities with a digital device has a positive influence on the intention to do it.

In order to understand to which extent the external, healthrelated lever of adoption (i.e., the doctor) is able to motivate users to adopt the technologies, we further investigated the role of individuals' health literacy in adopting the technologies [23]. Despite consumers are more and more inclined to look for information in different media and channels [24], [25], health literacy could be still improved [26]. Patients with low literacy experience poorer general health status and use of health resources [27], [28]. Grounding on that, we hypothesize that users more aware about healthcare and more prone to autonomously look for healthrelated information through digital channels, should modify their model of behavior with respect to the users that are less literate in this regards. More formally:

H3. The confidence an individual has on searching for health information on internet has an influence on the adoption of digital technologies to monitor lifestyle.

\section{A. Overall model}

The conceptual model on which this study is base is depicted in Fig.1. The model includes also four control variables that are consistent with past research on user acceptance models in wearable settings [3]: age, level of education, frequency of sport activities and the presence of a chronic disease.

\section{METHODS}

To ensure content validity we developed our questionnaire by building on previous theoretical basis. To assure face validity, pre-testing was conducted using a focus group involving academics from the field and semi-structured interviews with selected participants who were not included in the subsequent research. We used a structured questionnaire mostly based on a ten-point Likert scale (for further details, see Table I in
Appendix). Measurement items were developed based on the literature review [29]-[32] and supported by expert opinions.

The data were collected through a survey administered to 1,000 citizens who are statistically representative of the Italian population (see Table II in Appendix). The participants were given introduction letters that explained the aims and the procedures of the study.

Data analysis was carried out using Partial Least Square Structural Equation Modeling (PLS-SEM), a secondgeneration multivariate data analysis method that enables to test linear and additive models. PLS-SEM is increasingly adopted in the healthcare research, as it permits to analyze composite models in a robust way [33] and does not present the constraints of first-generation techniques toward causal and complex modeling analysis. Among second- generation techniques, PLS-SEM has been preferred to covariance-based SEM, due to the explorative type of research and the complexity of the structural model (several constructs and indicators) [34].The estimation and data manipulation were performed using SmartPLS3. We opted for PLS-SEM due to the explorative type of research [35]. We performed a path analysis on the full model and further conducted a multi-group comparison between subjects with a low Online Health Literacy (below sample average) against subjects with a high Online Health Literacy (above sample average). Our sample size was satisfactory, being more than 10-times the largest number of structural paths directed to a particular latent construct in the structural model [36]. Our model was balanced in the weight of endogenous and exogenous constructs, meeting PLS-SEM's prediction goal [37].

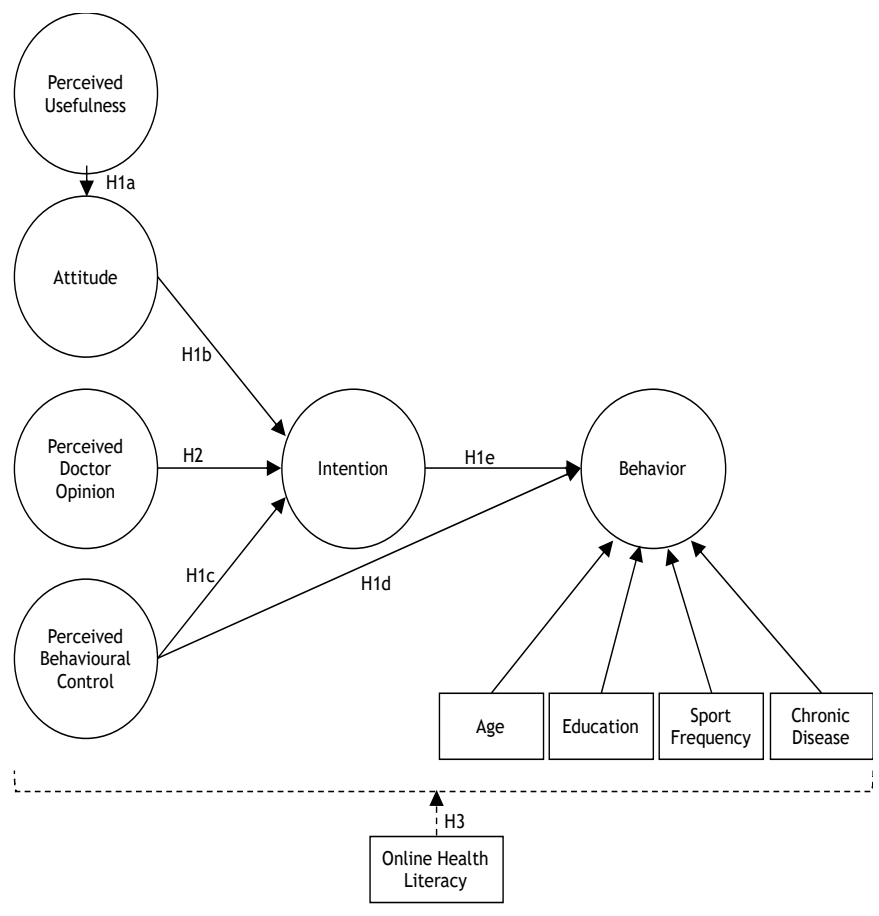

Fig. 1. Conceptual model and related hypotheses 


\section{RESULTS}

\section{A. Measurement of reliability and validity}

We firstly examined the reliability and validity measures for the model constructs (see Table III in Appendix). The number of iterations to find convergence was 5, suggesting the goodness of the model [38].

We measured composite reliability and Cronbach's alpha, as tests of convergent validity in reflective models (for a discussion see [39]). All our values exceed the suggested threshold of 0.7 for both composite reliability and Chronbach's alpha, thus confirming the validity of our model.

We used AVE, reflecting the average communality for each latent factor in a reflective model, as a test of both convergent and divergent validity. AVE values were above the threshold of 0.5 [40], [41] indicating convergent validity, thus the latent construct ability to explain a great share of the variance of its indicators. Further, we establish discriminant validity by the Fornell-Larcker criterion [42], which assesses discriminant validity on the construct level, by assessing that the square root of AVE is higher than its correlation with any other latent variable. All our AVE square roots were satisfying this condition. At the indicator level, we evaluated discriminant validity by assessing that the loading of each indicator is greater than all of its cross-loadings [40]. We satisfied this criterion as well.

As a measure of fit of the model, we evaluated the standardized root mean square residual (SRMR). Our model has a SRMR below the suggested maximum value of 0.08 [43] thus confirming the good fit.

Finally, we checked our model for structural multicollinearity. Our structural Variance Inflation Factor (VIF) coefficients are lower than 4 [34], suggesting that multicollinearity is not an issue in our model.

\section{B. Results of model estimation}

After validating the measurement model, the hypothesized relationships among the constructs were tested. A bootstrapping with 5,000 samples was conducted [34]. The structural model was then assessed by examining the determination coefficients, the path coefficients and their significance levels.

As shown in Fig. 2, hypotheses $\mathrm{H} 1(\mathrm{a}, \mathrm{b}, \mathrm{c}, \mathrm{d}, \mathrm{e})$ and $\mathrm{H} 2$ are fully supported, with path coefficients significant at the 0.05 significance level and below. Individual-specific variables of age, education and sport frequency shown a significant, even if small, influence. The presence of a chronic disease instead does not have influence on the adoption of digital technologies to monitor lifestyle. The coefficient of determination $\mathrm{R}^{2}$ is of 0.309 for attitude, 0.569 for intention and 0.336 for behavior, representing adequate effects for our model.

Blindfolding technique [44] was used as a measure of predictive relevance of the model, by calculating the $\mathrm{Q}^{2}$ value [45], [46]. $\mathrm{Q}^{2}$ values above zero indicate that the observed values are adequate reconstructed and that the model has predictive relevance [47]. The $\mathrm{Q}^{2}$ value of cross-validated redundancy is 0.204 for attitude, 0.476 for intention and 0.202 for behavior, showing respectively medium to large effect size according to [48].

\section{Multi-group Analysis (MGA)}

PLS multigroup analysis has been used to assess if the proposed model differs between individuals with high and with low online health literacy. Two groups were defined discriminating on the OHL mean (5.09) resulting in 490 subjects with high OHL and 414 subjects with low OHL. A bootstrapping with 5,000 samples has been conducted [34].

Path coefficients, standard deviations and coefficient of determination $\mathrm{R}^{2}$ for the two groups are reported in Table IV in Appendix. The results of the non-parametric significance test for the difference between group-specific path coefficients are reported as well (see [47], [49]). As noted, a significant difference ( $p$-value $<0.05$ ) between the two groups is found for the following relationships: attitude on intention, intention on behaviors and perceived behavioral control on behavior. The other paths do not show differences between the groups, thus only partially supporting $\mathrm{H} 3$.

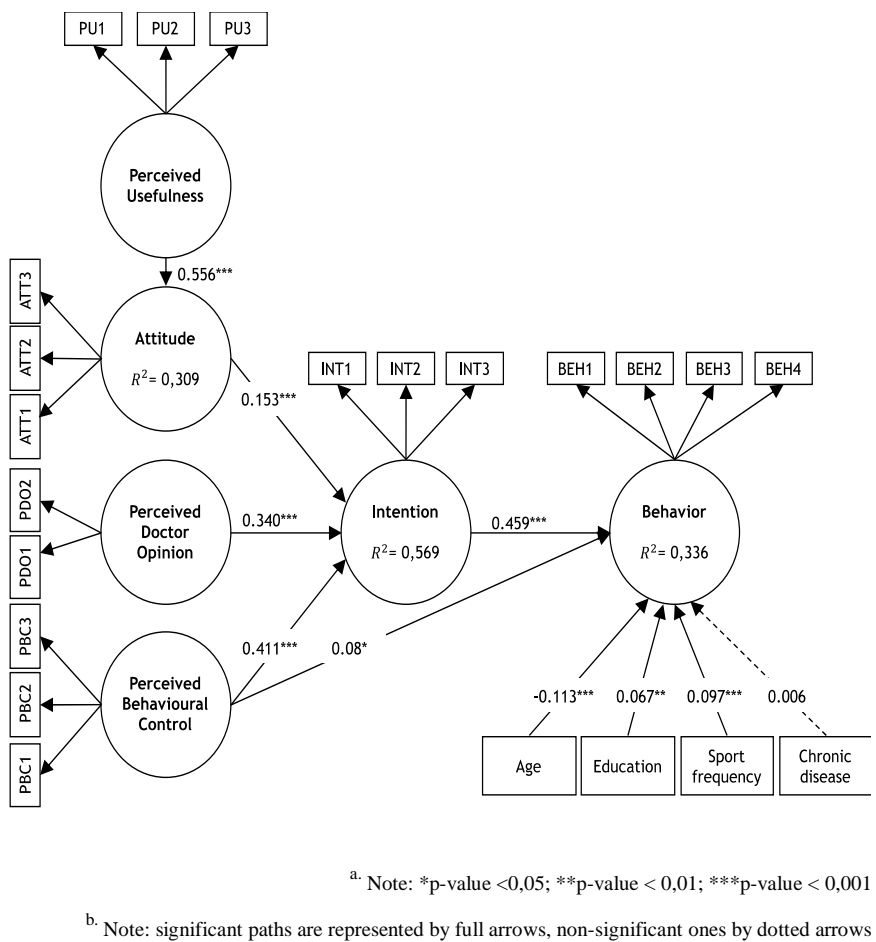

Fig. 2. Structural Model Results 


\section{DISCUSSION, CONCLUSIONS AND IMPLICATIONS}

The results of the study raise a number of relevant implications for academicians, practitioners and policy makers. First and foremost, the study demonstrates how the Theory of Planned Behavior [14] may describe and explain the adoption of digital technologies for lifestyle monitoring, showing in particular that the process is significantly cognitive in nature, given the strong relationship between intention and behavior. As emerged in other studies [50], [51], a direct though not particularly strong - relationship between Perceived Behavioral Controls and Behavior emerges, raising the idea that habits and confidence in the instruments may be a good driver of adoption, even beyond the intrinsic intention to adopt. Remarkably, Attitude results strongly determined by the construct of Perceived Usefulness, testifying that the opinion on these devices is still strongly tied to the perception of their functional value [52]. What characterizes our results, yet, is the fact that, compared to traditional TPB-based studies, our work shows that Perceived Doctor Opinion (the stronger Subjective Norm we may imagine in this adoption process) and Perceived Behavioral Control play a stronger role in the development of an Intention than Attitude. This is a remarkable result, in that it shows that the adoption of digital technologies for lifestyle monitoring depends not only on personal beliefs, but also, and probably foremost, on the perception of appreciation by the doctors and by the perception of ability to buy and use the technology. This outcome lets hypothesize that the main driver of adoption is external in nature, and highlights the weight and importance of third parties', authoritative influencers in increasing the intention to adopt and, in turn, the actual adoption of lifestyle monitoring technologies. This is strongly supported by the outcomes of $\mathrm{H} 3$ testing, showing that Online Health Literacy boosts the internal motivations to adopt, i.e., the role of attitude in TPB. These findings open the way to further research on the external drivers of adoption, less investigated in TPB-based models but which show to be relevant in lifestyle-related decision-making processes. It would be particularly interesting to understand if similar external influence is in place for other consumer healthcare technologies. The analysis of the covariates further shows that in our sample, which is a reliable (both in terms of size and composition) representation of the Italian population, the digital technologies for Lifestyle monitoring are particularly adopted by younger, more educated and sporty users, while there is not an apparent influence of the presence of chronic diseases in the adoption process. This outcome shows how, besides the external nature of the adoption process, cultural patterns are of the essence in this kind of innovation diffusion. A deeper investigation of the effect of culture on personal technologies adoption is suggested, for instance through studies conducted on different audiences and welfare conditions. This suggests practitioner and policy makers alike to advance proper communication and promotion campaigns towards elder and less educated layers of the population to increase their actual adoption. Fostering a closer relationship between patients and doctors may improve the adoption of technologies for lifestyle monitoring as well. The results of our study show that the potentially most effective levers of communication refer to an increase of doctors' awareness on the usefulness of these solutions (of course, if existing), but also on their ease of use by the users.

TABLE I. INDICATOR OF THE MEASUREMENT MODEL

\begin{tabular}{|c|c|c|}
\hline Construct & Label & Indicator \\
\hline \multirow{3}{*}{ Attitude } & ATT1 & Heath rate monitoring is important for staying well \\
\hline & ATT2 & Steps monitoring is important for staying well \\
\hline & ATT3 & Training monitoring is important for staying well \\
\hline \multirow{4}{*}{ Behavior } & BEH1 & Usage of apps to monitor hearth rate \\
\hline & $\mathrm{BEH} 2$ & Usage of apps to monitor steps \\
\hline & $\mathrm{BEH} 3$ & Usage of apps to monitor training through the wearable device \\
\hline & $\mathrm{BEH} 4$ & Usage of apps to monitor calories through the wearable device \\
\hline \multirow{3}{*}{ Intention } & INT1 & I planned to monitor my lifestyle with digital devices in the upcoming months \\
\hline & INT2 & It is probable that I'll monito my lifestyle with digital devices in the upcoming months \\
\hline & INT3 & I intent monitoring my lifestyle with digital devices in the upcoming months \\
\hline Perceived & $\mathrm{PBC1}$ & I have enough time to monitor my lifestyle with digital devices \\
\hline Behavioral & $\mathrm{PBC} 2$ & I have enough economic resources to monitor my lifestyle with digital devices \\
\hline Control & $\mathrm{PBC} 3$ & Monitoring my lifestyle with digital devices is easy \\
\hline \multirow{2}{*}{$\begin{array}{l}\text { Perceived Doctor } \\
\text { Opinion }\end{array}$} & PDO1 & My doctor thinks that I should monitor my lifestyle with digital devices \\
\hline & $\mathrm{PDO} 2$ & My doctor expects me to monitor my lifestyle with digital devices \\
\hline \multirow{3}{*}{$\begin{array}{l}\text { Perceived } \\
\text { usefulness }\end{array}$} & PU1 & Monitoring my lifestyle with digital devices would improve my health conditions \\
\hline & PU2 & Monitoring my lifestyle with digital devices would enable me to maintain healthy \\
\hline & PU3 & Monitoring my lifestyle with digital devices is useful \\
\hline \multirow{2}{*}{$\begin{array}{l}\text { Online Health } \\
\text { Literacy }\end{array}$} & OHL1 & I know how to use internet for answering to questions about my health condition \\
\hline & OHL2 & I am able distinguishing valuable resources from unevaluable one while searching online for health information \\
\hline \multirow{4}{*}{$\begin{array}{l}\text { Control } \\
\text { variables }\end{array}$} & EDU & $\begin{array}{l}\text { Education }[9=\text { University degree; } 8=\text { Univ. without diploma; } 7=\text { College degree; } 6=\text { College without diploma } 5=\text { High school degree; } \\
4 \text { = High School without diploma } 3=\text { Elementary school degree } ; 2=\text { Elementary school without diploma; } 1=\text { no education }]\end{array}$ \\
\hline & SPORT & $\begin{array}{l}\text { Frequency of sport activities }[6=\text { three times per week; } 5=\text { once a week; } 4=\text { once a month; } 3=\text { once a year; } 2=\text { less than once a year; } 1 \\
=\text { never] }\end{array}$ \\
\hline & CHR & Presence of a chronic diseases $[1=\mathrm{Yes} ; 0=\mathrm{No}]$ \\
\hline & AGE & Age of the respondent in years \\
\hline
\end{tabular}


TABLE II. SAMPLE DEMOGRAPHIC CHARACTERISTICS

\begin{tabular}{ll|l}
\hline Gender & Results & Education \\
\hline Male & $48 \%$ & Eesults \\
Female & $52 \%$ & Elementary school \\
\hline Age & Results & High school junior \\
\hline $15-17$ & $3 \%$ & High school \\
$18-24$ & $8 \%$ & University \\
$25-34$ & $13 \%$ & Place of residence \\
$35-44$ & $18 \%$ & City \\
$45-54$ & $18 \%$ & Town \\
$55-64$ & $15 \%$ & City/town size \\
$65-74$ & $16 \%$ & Less than 30000 inhabitants \\
$>74$ & $9 \%$ & From 30.000 to 100.000 inhabitants \\
\hline
\end{tabular}

TABLE III. DESCRIPTIVE STATISTICS, RELIABILITY AND VALIDITY MEASURES

\begin{tabular}{|c|c|c|c|c|c|c|c|c|c|}
\hline \multirow[t]{2}{*}{ Constructs } & \multicolumn{4}{|c|}{ Estimates } & \multirow[t]{2}{*}{ Indicators } & \multicolumn{4}{|c|}{ Final model } \\
\hline & Cronbach $\alpha$ & Rho_A & Reliability & $A V E$ & & Valuable obs. & Mean & Std. Dev & Loadings \\
\hline \multirow[t]{3}{*}{ Attitude } & 0.785 & 0.788 & 0.874 & 0.699 & ATT1 & 953 & 7.406 & 2.607 & 0.821 \\
\hline & & & & & ATT2 & 943 & 6.017 & 2.967 & 0.838 \\
\hline & & & & & ATT3 & 934 & 6.278 & 2.920 & 0.849 \\
\hline \multirow[t]{4}{*}{ Behavior } & 0.814 & 0.815 & 0.877 & 0.641 & BEH1 & 1000 & 1.421 & 0.685 & 0.774 \\
\hline & & & & & $\mathrm{BEH} 2$ & 1000 & 1.327 & 0.639 & 0.815 \\
\hline & & & & & BEH3 & 1000 & 1.322 & 0.622 & 0.813 \\
\hline & & & & & $\mathrm{BEH} 4$ & 1000 & 1.304 & 0.581 & 0.800 \\
\hline \multirow[t]{3}{*}{ Intention } & 0.937 & 0.937 & 0.960 & 0.888 & INT1 & 949 & 3.906 & 2.988 & 0.942 \\
\hline & & & & & INT2 & 945 & 4.013 & 2.992 & 0.943 \\
\hline & & & & & INT3 & 950 & 4.031 & 3.067 & 0.942 \\
\hline Perceived & 0.762 & 0.772 & 0.863 & 0.677 & PBC1 & 949 & 4.897 & 2.969 & 0.847 \\
\hline Behavioral & & & & & $\mathrm{PBC} 2$ & 927 & 4.790 & 2.936 & 0.768 \\
\hline Control & & & & & $\mathrm{PBC} 3$ & 907 & 5.490 & 2.864 & 0.851 \\
\hline \multirow[t]{2}{*}{ Perceived Doctor Opinion } & 0.764 & 0.766 & 0.894 & 0.809 & PDO1 & 860 & 5.098 & 2.929 & 0.893 \\
\hline & & & & & $\mathrm{PDO} 2$ & 910 & 3.754 & 2.779 & 0.906 \\
\hline Perceived & 0.899 & 0.899 & 0.937 & 0.831 & PU1 & 935 & 5.084 & 2.993 & 0.913 \\
\hline \multirow{2}{*}{ Usefulness } & & & & & PU2 & 942 & 5.134 & 2.979 & 0.915 \\
\hline & & & & & PU3 & 951 & 5.472 & 2.998 & 0.907 \\
\hline Online Health & - & - & - & - & OHL1 & 928 & 5.109 & 3.052 & - \\
\hline Literacy & & & & & OHL2 & 921 & 4.988 & 2.866 & - \\
\hline Education & - & - & - & - & EDU & 1000 & 6.491 & 1.570 & - \\
\hline Sport Frequency & - & - & - & - & SPORT & 1000 & 3.612 & 2.104 & - \\
\hline Chronic Diseases & - & - & - & - & CHR & 1000 & 0.286 & 0.452 & - \\
\hline Age & - & - & - & - & AGE & 1000 & 52.51 & 16.60 & - \\
\hline
\end{tabular}

TABle IV. Multi-Group AnAlysis Results

\begin{tabular}{|c|c|c|c|c|c|}
\hline & \multicolumn{2}{|c|}{ OHL_HIGH $(\mathrm{N}=490)$} & \multicolumn{2}{|c|}{ OHL_LOW $(N=414)$} & \multirow{2}{*}{$\begin{array}{c}\text { GROUP DIFFERENCES } \\
\text { (| OHL.HIGH - OHL.LOW |) } \\
\text { Path coefficients }\end{array}$} \\
\hline & Path coefficients & Std. dev & Path coefficients & Std. dev & \\
\hline Attitude $\rightarrow$ Intention & $0.224 * * *$ & 0.038 & $0.110^{* *}$ & 0.038 & $0.114^{*}$ \\
\hline Intention $\rightarrow$ Behavior & $0.516^{* * *}$ & 0.048 & $0.316 * * *$ & 0.072 & $0.199 * *$ \\
\hline Perceived Behavioral Control $\rightarrow$ Behavior & 0.026 & 0.047 & $0.190 * *$ & 0.062 & $0.164 *$ \\
\hline Perceived Behavioral Control $\rightarrow$ Intention & $0.407 * * *$ & 0.043 & $0.360 * * *$ & 0.054 & 0.047 \\
\hline Perceived Doctor Opinion $\rightarrow$ Intention & $0.303 * * *$ & 0.048 & $0.396 * * *$ & 0.059 & 0.094 \\
\hline Perceived Usefulness $\rightarrow$ Attitude & $0.499 * * *$ & 0.040 & $0.560 * * *$ & 0.034 & 0.062 \\
\hline Age $\rightarrow$ Behavior & $-0.100 *$ & 0.044 & $-0.132 * *$ & 0.045 & 0.032 \\
\hline Chronic disease $\rightarrow$ Behavior & -0.037 & 0.039 & 0.055 & 0.045 & 0.092 \\
\hline Education $\rightarrow$ Behavior & 0.053 & 0.039 & 0.073 & 0.042 & 0.020 \\
\hline Sport frequency $\rightarrow$ Behavior & $0.129 * * *$ & 0.035 & 0.054 & 0.042 & 0.075 \\
\hline Attitude & $R^{2}$ & & $R^{2}$ & & \\
\hline Behavior & 0.249 & & 0.314 & & \\
\hline Intention & 0.339 & & 0.267 & & \\
\hline & 0.539 & & 0.529 & & \\
\hline
\end{tabular}

\section{REFERENCES}

[1] R. Wright and L. Keith, "Wearable technology: If the Tech Fits, Wear It," J. Electron. Resour. Med. Libr., vol. 11, no. 4, pp. 204-216, 2014.

[2] P. B. Shull, W. Jirattigalachote, M. A. Hunt, M. R. Cutkosky, and S. L. Delp, "Quantified self and human movement: A review on the clinical impact of wearable sensing and feedback for gait analysis and intervention," Gait Posture, vol. 40, pp. 11-19, 2014.
[3] M. Kalantari, "Consumers adoption of wearable technologies: literature review, synthesis, and future research agenda," Int. J. Technol. Mark. vol. 12, no. 1, p. 1, 2017.

[4] Y. H. Wang and C. C. Hsieh, "Explore technology innovation and intelligence for IoT (Internet of Things) based eyewear technology," Technol. Forecast. Soc. Change, vol. 127, pp. 281-290, 2018.

[5] D. Bettiga and L. Lamberti, "Exploring the adoption process of personal technologies: A cognitive-affective approach," J. High Technol. Manag. 
Res., vol. 28, no. 2, 2017.

[6] D. Bettiga, L. Lamberti, and E. Lettieri, "Individuals' adoption of smart technologies for preventive health care: a structural equation modeling approach," Health Care Manag. Sci., no. In Press., Jan. 2019.

[7] J. T. Cohen, P. J. Neumann, and M. C. Weinstein, "Does Preventive Care Save Money? Health Economics and the Presidential Candidates," N. Engl. J. Med., vol. 358, no. 7, pp. 661-663, Feb. 2008.

[8] H. Tanawat and K. P. Audhesh, "Consumer innovativeness and perceived risk: implications for high technology product adoption," $J$. Consum. Mark., vol. 23, no. 4, pp. 182-198, 2006

[9] D. Bettiga, L. Lamberti, and G. Noci, "Do mind and body agree? Unconscious versus conscious arousal in product attitude formation," $J$. Bus. Res., vol. 75, pp. 108-117, 2017.

[10] D. Bettiga and L. Lamberti, "Exploring the role of anticipated emotions in product adoption and usage," J. Consum. Mark., vol. 35, no. 3, pp. 300-316, May 2018.

[11] F. D. Davis, "User acceptance of information technology: system characteristics, user perceptions and behavioral impacts," Int. J. Man. Mach. Stud., vol. 38, no. 3, pp. 475-487, Mar. 1993.

[12] V. Venkatesh and F. D. Davis, "A Theoretical Extension of the Technology Acceptance Model: Four Longitudinal Field Studies," Manage. Sci., vol. 46, no. 2, pp. 186-204, Feb. 2000.

[13] R. Holden and B. Karsh, "The Technology Acceptance Model: Its past and its future in health care," J. Biomed. Inform., vol. 43, no. 1, pp. 159-172, 2010

[14] I. Ajzen, "The theory of planned behavior," Organ. Behav. Hum. Decis. Process., vol. 50, no. 2, pp. 179-211, Dec. 1991.

[15] T. J. Madden, P. S. Ellen, and I. Ajzen, "A Comparison of the Theory of Planned Behavior and the Theory of Reasoned Action," Personal. Soc. Psychol. Bull., vol. 18, no. 1, pp. 3-9, Feb. 1992.

[16] H. Steinmetz, M. Knappstein, I. Ajzen, P. Schmidt, and R. Kabst, "How effective are behavior change interventions based on the theory of planned behavior?: A three-level meta analysis," Zeitschrift fur Psychologie / Journal of Psychology, vol. 224, no. 3. pp. 216-233, Jul2016.

[17] I. Ajzen, "Consumer Attitudes and Behavior: the Theory of Planned Behavior Applied to Food Consumption Decisions," Riv. di Econ. Agrar., vol. 2, pp. 121-138, 2015.

[18] D. Riebl, S. K., Estabrooks, P. A., Dunsmore, J. C., Savla, J., Frisard, M. I., Dietrich, A. M, Y., Peng, X., Zhang, B.M., "A systematic literature review and meta-analysis: The Theory of Planned Behavior's application to understand and predict nutrition-related behaviors in youth," Eating Behaviors, vol. 18. pp. 160-178, 2015.

[19] L. M. Bohon, K. A. Cotter, R. L. Kravitz, P. C. Cello, and E. Fernandez y Garcia, "The Theory of Planned Behavior as it predicts potential intention to seek mental health services for depression among college students," J. Am. Coll. Heal., vol. 64, no. 8, pp. 593-603, Nov. 2016.

[20] M. S. Hagger, D. K. C. Chan, C. Protogerou, and N. L. D. Chatzisarantis, "Using meta-analytic path analysis to test theoretical predictions in health behavior: An illustration based on meta-analyses of the theory of planned behavior," Prev. Med. (Baltim)., vol. 89, pp. 154$161,2016$.

[21] D. P. Cooke, R., Dahdah, M., Norman, P., \& French, "How well does the theory of planned behaviour predict alcohol consumption? A systematic review and meta-analysis," Health Psychol. Rev., vol. 102, no. 2, pp. 148-167, 2013.

[22] L. Ong, J. C. J. M. de Haes, A. M. Hoos, and F. B. Lammes, "Doctorpatient communication: A review of the literature," Soc. Sci. Med., vol. 40, no. 7, pp. 903-918, 2003.

[23] R. E. Rudd, "The evolving concept of Health literacy : New directions for health literacy studies," J. Commun. Healthc., vol. 8, no. 1, pp. 7-9, 2015.

[24] D. Bettiga, A. Boaretto, and S. Chen, "Exploring media convergence: Evidence from Italy," Int. J. Eng. Bus. Manag., vol. 5, no. 1, pp. 1-9, Jan. 2013.

[25] L. Fernández-Luque and T. Bau, "Health and social media: Perfect storm of information," Healthcare Informatics Research, vol. 21, no. 2. pp. 67-73, 2015.

[26] K. Sørensen et al., "Health literacy and public health: A systematic review and integration of definitions and models," BMC Public Health, vol. 12, no. 1. p. 80, Dec-2012.

[27] D. A. DeWalt, N. D. Berkman, S. Sheridan, K. N. Lohr, and M. P.
Pignone, "Literacy and health outcomes," J. Gen. Intern. Med., vol. 19, no. 12 , pp. 1228-1239, Dec. 2004

[28] N. D. Berkman, S. L. Sheridan, K. E. Donahue, D. J. Halpern, and K. Crotty, "Low health literacy and health outcomes: An updated systematic review," Annals of Internal Medicine, vol. 155, no. 2. pp. 97-107, 2011.

[29] L. H. Wu, L. C. Wu, and S. C. Chang, "Exploring consumers' intention to accept smartwatch," Comput. Human Behav., vol. 64, pp. 383-392, Nov. 2016.

[30] H. Li, J. Wu, Y. Gao, and Y. Shi, "Examining individuals' adoption of healthcare wearable devices: An empirical study from privacy calculus perspective," Int. J. Med. Inform., vol. 88, pp. 8-17, Apr. 2016.

[31] S. C. Jeong, S.-H. Kim, J. Y. Park, and B. Choi, "Domain-specific innovativeness and new product adoption: A case of wearable devices," Telemat. Informatics, vol. 34, no. 5, pp. 399-412, Aug. 2017.

[32] H. Yang, J. Yu, H. Zo, and M. Choi, "User acceptance of wearable devices: An extended perspective of perceived value," Telemat. Informatics, vol. 33, no. 2, pp. 256-269, May 2016.

[33] N. K. Avkiran, "An in-depth discussion and illustration of partial least squares structural equation modeling in health care," Health Care Manag. Sci., vol. 21, no. 3, pp. 401-408, Feb. 2018.

[34] J. Hair, C. Ringle, and M. Sarstedt, "PLS-SEM: Indeed a silver bullet," J. Mark. Theory Pract., vol. 19, no. 2, pp. 139-152, 2011.

[35] H. Hwang, N. Malhotra, Y. Kim, M. A. Tomiuk, and S. Hong, "A comparative study on parameter recovery of three approaches to structural equation modeling," J. Mark. Res., vol. 47, no. 4, pp. 699$712,2010$.

[36] D. Barclay, C. Higgins, and R. Thompson, "The Partial Least Squares (PLS) Approach to Causal Modelling: Personal Computer Adoption and Use as an Illustration," Technol. Stud., vol. 2, no. 2, pp. 285-309, 1995.

[37] J. Hair, M. Sarstedt, C. Ringle, and J. Mena, "An assessment of the use of partial least squares structural equation modeling in marketing research," J. Acad. Mark. Sci., vol. 40, no. 3, pp. 413-433, 2012.

[38] K. Wong, "Partial least squares structural equation modeling (PLSSEM) techniques using SmartPLS," Mark. Bull., vol. 24, no. 1, pp. 132,2013

[39] C. Werts, R. Linn, and K. Jöreskog, "Intraclass reliability estimates: Testing structural assumptions," Educ. Psychol. Meas., vol. 34, no. 1, pp. 25-33, 1974.

[40] W. Chin, "The partial least squares approach to structural equation modeling," Mod. methods Bus. Res., vol. 295, no. 2, pp. 295-336, 1998.

[41] R. P. Bagozzi and Y. Yi, "On the evaluation of structural equation models," J. Acad. Mark. Sci., vol. 16, no. 1, pp. 74-94, 1988.

[42] C. Fornell and D. Larcker, "Evaluating structural equation models with unobservable variables and measurement error," J. Mark. Res., vol. 18, no. 1 , pp. 39-50, 1981.

[43] L. T. Hu and P. M. Bentler, "Cutoff criteria for fit indexes in covariance structure analysis: Conventional criteria versus new alternatives,' Struct. Equ. Model., vol. 6, no. 1, pp. 1-55, Jan. 1999.

[44] M. Tenenhaus and V. Vinzi, "PLS path modeling," Comput. Stat. Anal., vol. 48, no. 1, pp. 159-205, 2005.

[45] M. Stone, "Cross-validatory choice and assessment of statistical predictions," J. R. Stat. Soc. Ser. B, vol. 36, no. 2, pp. 111-147, 1974.

[46] S. Geisser, "A predictive approach to the random effect model," Biometrika, vol. 61, no. 1, pp. 101-107, 1974

[47] J. Henseler and G. Fassott, "Testing moderating effects in PLS path models: An illustration of available procedure," in Handbook of Partial Least Squares, no. July, Springer Berlin Heidelberg, 2010, pp. 171-193.

[48] J. Cohen, Statistical power analysis for the behavioral sciences. Hillsdale, New Jersey: Lawrence Erlbaum Associates, 1988.

[49] M. Sarstedt, J. Henseler, and C. Ringle, "Multigroup analysis in partial least squares (PLS) path modeling: Alternative methods and empirical results," Adv. Int. Mark., vol. 22, no. 1, pp. 195-218, 2011.

[50] I. Ajzen and T. J. Madden, "Prediction of goal-directed behavior: Attitudes, intentions, and perceived behavioral control," J. Exp. Soc. Psychol., vol. 22, no. 5, pp. 453-474, 1986.

[51] G. Godin and G. Kok, "The Theory of Planned Behavior: A Review of its Applications to Health-Related Behaviors," Am. J. Heal. Promot., vol. 11, no. 2, pp. 87-98, Nov. 1996

[52] J. N. Sheth, B. I. Newman, and B. L. Gross, "Why we buy what we buy: A theory of consumption values," J. Bus. Res., vol. 22, no. 2, pp. 159170, Mar. 1991 